\title{
NO ATUAL CENÁRIO ECONÔMICO QUAIS OS BENEFÍCIOS TRAZIDOS PELA LEI DE FALÊNCIA E RECUPERAÇÃO JUDICIAL PARA SOCIEDADE BRASILEIRA?
}

Kaio Caldeira dos Anjos, Matheus Henrique Vinha da Silva, Thais Rubia Ferreira Lepre

Universidade do Oeste Paulista - UNOESTE, curso de Ciências Contábeis, Presidente Prudente, SP. E-mail: thaisrubia@unoeste.br

\section{RESUMO}

Com a regulamentação da Lei n. 11.101, de 09 de Fevereiro de 2005, em que a finalidade era de ajudar a recuperar as empresas que estiverem diante de momento de crise financeira, o número de pedidos de falência tem diminuído a cada ano, com o intuito de manter a função social da empresa. Diante disso, se faz necessário descobrir quais são os benefícios que a regulamentação dessa lei proporcionou a sociedade brasileira, considerando o atual cenário econômico? Justificando a existência deste estudo que visa discutir esta questão, beneficiando a sociedade em geral, com informações acerca desta nova lei, considerando que este artigo tem como objetivo identificar os benefícios que a lei de falência e recuperação judicial trouxe para a sociedade no atual cenário econômico do país. E para tanto, este artigo contou com uma abordagem qualitativa, tendo a pesquisa bibliográfica como único instrumento de coleta de dados. Onde foi possível concluir que todos os benefícios que a manutenção das empresas no mercado traz para sociedade estão relacionados a geração de emprego e renda.

Palavras Chaves: Recuperação. Falência. Sociedade. Função Social. Benefícios.

\section{IN THE CURRENT ECONOMIC SCENARIO WHAT ARE THE BENEFITS LAID DOWN BY THE LAW OF FAILURE AND JUDICIAL RECOVERY FOR BRAZILIAN SOCIETY?}

\begin{abstract}
With the regulation of Law no. 11.101, of February 9, 2005, the purpose of which was to help companies recovering from the financial crisis, the number of bankruptcy petitions has been reduced every year in order to maintain the company's social function. company. Given this, it is necessary to discover what are the benefits that the regulation of this law provided the Brazilian society, considering the current economic scenario? Justifying the existence of this study that aims to discuss this issue, benefiting society in general, with information about this new law, considering that this article aims to identify the benefits that the law of bankruptcy and judicial recovery brought to society in the current economic scenario from the country. To this end, this article had a qualitative approach, with bibliographic research as the only instrument for data collection. Where it was possible to conclude that all the benefits that the maintenance of the companies in the market brings to society are related to the generation of employment and income.
\end{abstract}

Keywords: Recovery. Bankruptcy. Society. Social role. Benefits.

\section{INTRODUÇÃO}

Todos os dias um grande número de empresas iniciam suas atividades, e outras tantas encerram. Para sociedade, empresa funcionando é sinônimo de emprego e renda, pois quanto mais pessoas empregadas, maior é a movimentação na economia, gerando a necessidade de aumento da produção, que gera novos empregos e renda, ou seja, é circulo vicioso que depende da manutenção das empresas no mercado. 
Diante desta necessidade o governo brasileiro realizou uma modificação no decreto-lei $\mathrm{n}$. o 7.661, de 21 de junho de 1945, para nova lei da falência e recuperação judicial, Lei n. 11.101, de 09 de Fevereiro de 2005. A nova lei tem como objetivo a facilitação da Recuperação de empresas, assim como a manutenção dos empregos e da atividade produtiva do negócio, além de facilitar aos credores para receberem os direitos. Portanto, ela não se preocupa somente com os interesses dos credores, mas com a sociedade em geral que depende da atividade produtiva da empresa, justificando a existência deste artigo que visa discutir tal questão, beneficiando a sociedade em geral, com informações acerca desta nova lei, considerando que este artigo tem como objetivo identificar os benefícios que a lei de falência e recuperação judicial trouxe para a sociedade no atual cenário econômico do país.

\section{METODOLOGIA}

Esse artigo foi elaborado com base em uma abordagem qualitativa, que de acordo com Minayo (2003, p. 16-18) "é o caminho do pensamento a ser seguido. Ocupa um lugar central na teoria e trata-se basicamente do conjunto de técnicas a ser adotada para construir uma realidade". A pesquisa é assim, a atividade básica da ciência na sua construção da realidade. A pesquisa qualitativa, no entanto, trata-se de uma atividade da ciência, que visa a construção da realidade, mas que se preocupa com as ciências sociais em um nível de realidade que não pode ser quantificado.

E coerentemente com esta abordagem, este artigo utilizou como instrumento de coleta de informações, a pesquisa bibliográfica que para Marconi e Lakatos (2010, p. 142) “[...] é um apanhado geral sobre os principais trabalhos já realizados, revestidos de importância, por serem capazes de fornecer dados atuais e relevantes relacionados com o tema". Realizada tendo como base, livros, artigos já publicados, e leis.

\section{RESULTADOS}

A Lei n. 11.101, de 09 de Fevereiro de 2005, que regulamenta a recuperação judicial, extrajudicial e a falência do empresário e da sociedade empresária, embasada no projeto de lei $n$. 4.376 de 1993, foi criada com a finalidade de ajudar a recuperar as empresas que estiverem diante de momento de crise financeira, onde devem ter um amparo especial na lei. O Art. 47, salienta essa ideia:

Art.47. A recuperação judicial tem por objetivo viabilizar a superação da situação de crise econômico-financeira do devedor, a fim de permitir a manutenção da fonte produtora, do emprego dos trabalhadores e dos interesses dos credores, promovendo, assim, a preservação da empresa, sua função social e o estímulo à atividade econômica.

Visando que o objetivo principal da lei é ofertar um auxilio para a manutenção das empresas no mercado, pensando também em sua função social e dando um estímulo a atividade desenvolvida, foi criada algumas condições para que as empresas possam fazer parte desse proveito jurídico. Dentre essas condições o principal requisito é a capacidade de se reorganizar, montar um plano de recuperação e, após isso, participar de uma assembleia com os credores, onde será possível mostrar a viabilidade da manutenção da empresa, com capacidade de mudar a atual situação e retornar a ter lucros. Com tudo, os custos de uma recuperação judicial são altos, por esse motivo as avaliações são feitas de todas as formas, identificando assim a viabilidade, Coelho (2005, p.384) sobre a recuperação judicial diz que:

Até 2005, a lei brasileira não estimulava soluções de mercado para a recuperação das empresas em estado crítico. Isso porque sancionava como ato de falência qualquer iniciativa do devedor no sentido de reunir seus 
credores para uma renegociação global das dívidas. A sociedade empresária que se arriscasse a convocar os credores para lhes submeter um plano qualquer de recuperação podia ter a falência requerida e decretada, frustrando-se assim a solução de mercado que tentara encaminhar.

Estamos vivendo um período difícil com relação aos pedidos de recuperação judicial, com números recordes de solicitações. Tudo isso se deve à deterioração da saúde financeira das companhias brasileiras. E isso ocorreu, devido à recessão econômica, que prejudicou a geração de caixa das empresas, e ao crédito caro e escasso.

Com base em pesquisas realizadas pelos órgãos, o número de pedidos de recuperação judicial cresce a cada ano, entre esses pedidos a maior parte são pequenas e médias empresas. Dados fornecidos pela Serasa Experian (2016) mostram que o número de pedidos de recuperação judicial entre Janeiro e Agosto de 2016 subiu em 61,2\% em relação ao mesmo período do ano de 2015, passando de 766 pedidos em 2015 para 1.287 em 2016.

Baseado nos dados fornecidos pela Serasa, o Jornal Estadão (2013) divulgou que apenas $1 \%$ das empresas que pedem recuperação judicial no Brasil conseguem sair do processo recuperadas, além disso, no período de 2005 a 2013 apenas 23\% das empresas tiveram os planos de recuperação aprovados pelos credores, nos anos seguintes entre 2015 a 2016 esse número aumento para $68 \%$ nas micro e pequenas empresas.

Além do número dos pedidos de recuperação judicial, a Serasa Experian também divulgou em 2016, dados sobre a falência de empresas no Brasil, assim como no caso da recuperação as micro e pequenas empresas foram as mais atingidas. Na figura a seguir se demonstra em números:

TABELA 1: Falência e recuperação judicial de acordo com o porte da empresa

\begin{tabular}{|l|c|c|c|}
\multicolumn{4}{c|}{ Análise Mensal } \\
\hline Instrumento/Porte & ago/15 & jul/16 & ago/16 \\
\hline Falência Requerida & $\mathbf{1 8 5}$ & $\mathbf{1 8 9}$ & $\mathbf{1 6 1}$ \\
\hline Micro e Pequena Empresa & 99 & 108 & 91 \\
\hline Média Empresa & 51 & 37 & 33 \\
\hline Grande Empresa & 35 & 44 & 37 \\
\hline Falência Decretada & $\mathbf{5 4}$ & $\mathbf{6 7}$ & $\mathbf{7 1}$ \\
\hline Micro e Pequena Empresa & 37 & 53 & 51 \\
\hline Média Empresa & 13 & 10 & 13 \\
\hline Grande Empresa & 4 & 4 & 7 \\
\hline Recuperação Jud. Requerida & $\mathbf{1 3 9}$ & $\mathbf{1 7 5}$ & $\mathbf{1 3 7}$ \\
\hline Micro e Pequena Empresa & 70 & 122 & 84 \\
\hline Média Empresa & 54 & 36 & 35 \\
\hline Grande Empresa & 15 & 17 & 18 \\
\hline Recuperação Jud. Deferida & $\mathbf{1 0 8}$ & $\mathbf{1 4 9}$ & $\mathbf{1 0 3}$ \\
\hline Micro e Pequena Empresa & 48 & 103 & 59 \\
\hline Média Empresa & 45 & 30 & 35 \\
\hline Grande Empresa & 15 & 16 & 9 \\
\hline Recuperação Jud. Concedida & $\mathbf{2 4}$ & $\mathbf{7 0}$ & $\mathbf{5 3}$ \\
\hline Recuperação Extrajud. Requerida & - & - & $\mathbf{2}$ \\
\hline Recuperação Extrajud. Homologada & - & - & - \\
\hline
\end{tabular}

Fonte: Serasa Experian (2016). 
Ou seja, conforme demonstrado, o número de pedidos de recuperação judicial aumentou muito, e a margem de aprovação do plano apresentado também, no ano de 2015 precisamente em Agosto a taxa de aprovação de uma Micro e Pequena empresa foi de $68 \%$, passando para $70 \%$ de Agosto de 2016. A maioria dos planos aprovados não é um projeto de reestruturação para tornar a empresa viável economicamente, e sim basicamente renegociações de dívidas.

Segundo Rabi (2016) "A crise afeta mais intensamente as pequenas empresas porque elas têm uma estrutura menor de capital, e menos condições de sobreviver por um tempo maior num ambiente econômico ruim". Também por terem menos recurso em caixa, as pequenas empresas têm menos capacidade de diversificar com suas receitas, de diversificar produtos. E, muitas vezes, suas receitas acabam sendo diminuídas ainda porque as grandes empresas param de contratar os serviços das pequenas para cortar seus próprios custos.

GRÁFICO 1 - Pedidos de recuperação judicial

\section{Pedidos de recuperação judicial \\ Variação em \%, por categoria de empresa, até novembro}

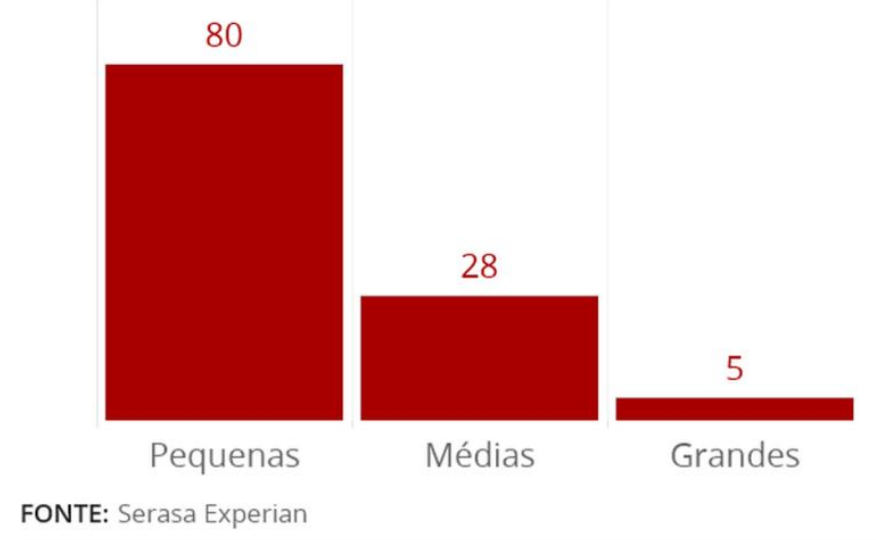

Fonte: Serasa Experian (2016).

Em uma nova pesquisa, realizada em Novembro/2016, foi realizado 113 pedidos de recuperação judicial, sendo deles $70 \%$ de Pequenas empresas e, apenas $4 \%$ de grandes empresas, justamente por serem capazes de suportar essa baixa.

Temos a empresa LBR uma das maiores empresas de produtos lácteos do País, que após o pedido de ingressar na recuperação judicial em 2013, e deferido o plano com os credores, manteve-se mais de 2.000 mil empregos, evitando assim um desastre na economia local.

Com isso a recuperação judicial apresenta-se como uma boa estratégia em momento de dificuldades econômicas para a empresa, tendo como objetivo principal preservar a empresa como entidade geradora de empregos, que paga seus tributos e que detém um potencial para a produção e circulação de bens e serviços, de acordo com Coelho (2008, p. 383), "a análise da viabilidade feita pelo judiciário deve observar cinco vetores: importância social, mão-de-obra e tecnologia empregada, volume do ativo e do passivo, idade da empresa e por fim o porte econômico", tendo assim como benefício principal a importância social, onde novamente volta ao ponto inicial de geração de empregos, manutenção de uma economia ativa no local em que a empresa está instalada, não deixando de observar o porte da empresa, pois uma empresa de grande porte gera em média mais de 500 empregos, temos recentemente o exemplo do frigorifico JBS que encerrou as atividades na unidade de Presidente Epitácio, onde contava com 795 funcionários, deixando assim a economia da cidade desestruturada. 
Mantendo a empresa em atividade, e conseguindo atingir o objetivo proposto no plano para iniciar a recuperação judicial, pode-se dizer que há benefícios para todos os envolvidos, como diz Konder (2005, p. 29), "a empresa é a celular essencial da economia de mercado e cumpre relevante função social, na medida em que, se explorar a atividade prevista em seu objeto e ao perseguir o seu objetivo, o lucro, promove interações econômicas com outros agentes do mercado, consumindo, vendendo, gerando empregos, pagando tributos, movimentando a economia, desenvolvendo a comunidade em que está inserida, enfim, criando riqueza e ajudando no desenvolvimento do país". O autor exemplifica vários beneficiados com a recuperação da empresa, tanto seus credores, como o fisco, como a economia, e seus próprios funcionários, deixando assim a entender que, a nova lei de falência e recuperação judicial foi criada para viabilizar a superação de crise econômica e financeira da empresa.

\section{CONCLUSÃO}

A manutenção das empresas no mercado é de interesse de toda sociedade em geral, tendo em vista que é das organizações que as pessoas conseguem os recursos necessários para sobrevivência. Neste sentido, esse artigo teve como objetivo identificar os benefícios que a lei de falência e recuperação judicial trouxe para a sociedade no atual cenário econômico do país.

E ao longo do estudo, com base nos dados coletados foi possível concluir que a aprovação da lei, fez com que muitas empresas se mantivessem abertas mesmo que, diante do momento atual, muitos empregos foram mantidos, gerando renda para várias famílias e oportunizando que continuem consumindo e movimentando a economia local. Chegando ao consenso que, o benefício não é só para o empresário, mas principalmente, para todos que estão envolvidos no processo da empresa e também toda a economia local.

\section{REFERÊNCIAS BIBLIOGRÁFICAS}

MARCONI, M. A.; LAKATOS, E. M. Fundamentos de metodologia científica. 7. ed. São Paulo: Atlas, 2010.

IG. Pedidos de recuperação judicial aumentam 61,2\% no acumulado de 2016, diz Serasa. Disponível em: <http://economia.ig.com.br/2016-09-05/empresas-recuperacao-falencia.html. Acesso em 02 Jul. 2017.

GLOBO. Pedidos de recuperação judicial crescem mais entre pequenas e médias empresas. Disponível em: <http://g1.globo.com/economia/pme/noticia/pedidos-de-recuperacao-judicialcrescem-mais-entre-pequenas-e-medias-empresas.ghtml. Acesso em 16 Jul. 2017.

ESTADÃO. Só $1 \%$ das empresas sai da recuperação judicial no Brasil. Disponível em: < http://economia.estadao.com.br/noticias/geral,so-1-das-empresas-sai-da-recuperacao-judicialno-brasil-imp-,1085558. Acesso em 16 Jul. 2017.

JurídicoCerto. Você sabia que a recuperação judicial pode ser uma boa estratégia? Disponível em: < http://blog.juridicocerto.com/2017/05/voce-sabia-que-a-recuperacao-judicial-pode-seruma-boa-estrategia.html. Acesso em 19 Jul. 2017.

Lei 11.101/2005. Disponível em: < http://www.planalto.gov.br/ccivil 03/ato20042006/2005/lei/l11101.html. Acesso em: 07 ago. 2017.

COELHO, F. U. Comentários à lei de falências e de recuperação de empresas. São Paulo: Saraiva, 2005. 
COELHO, F. U. Curso de Direito Comercial: Direito de Empresa. 9. ed. São Paulo. Editora Saraiva. 2008.

COMPARATO, F. K. A reforma da empresa. Revista de Direito Mercantil, Industrial, Econômico e Financeiro, Nova Série, a. 22, n. 50, p. 57-74, abr./jun. 1983; ANTUNES, José Engrácia. Estrutura e responsabilidade da empresa: o moderno paradoxo regulatório. Revista Direito GV, v. 1, n. 2, p. 29-68, 2005. 